\title{
CORRIGENDUM
}

\section{GETTING UNDER THE SKIN: THE IMMUNOGENETICS OF}

PSORIASIS

Anne M. Bowcock and James G. Krueger

Nature Reviews Immunology 5, 699-711 (2005)

At the time of publication, information received about the authors' competing interests was incomplete. The correct Competing Interests Statement follows. The authors declare competing financial interests: see web version for details. 